\title{
On the gaining of understanding: syntheses, themes and information analysis
}

\author{
David Bawden
}

\begin{abstract}
Methods for gaining qualitative understanding, in the specific sense defined by Jonathan Kvanvig, of sets of information instantiated in documents, in the context of library/information research, are reviewed and compared. A number of methods are relevant to this kind of study, including critical and systematic reviewing, meta-ethnography, historical analysis, philosophical analysis, content and discourse analysis, and grounded theory. It is concluded that, while such studies are carried out in library/information research, there is no agreement on the most appropriate methods. It is suggested that the most appropriate methodology is based on critical interpretive synthesis, carried out in the style of ethnographic, chronological or conceptual analysis.
\end{abstract}

\section{Introduction}

This paper focuses on research methods, usable in library and information science, for gaining understanding of a topic, concept or issue by systematic qualitative analysis and synthesis of a body of recorded information.

"Understanding" is used here with the specific meaning defined by the philosopher Jonathan Kvanvig, by which he distinguishes it from information, knowledge and truth. He suggests that:

understanding requires the grasping of explanatory and other coherence-making relationships in a large and comprehensive body of information. One can know many unrelated pieces of information, but understanding is achieved only when informational items are pieced together.

(Kvanvig, 2003, 192)

The object of understanding, that which is understood, is, for Kvanvig, not a number of single propositions, such as normally constitute knowledge for the philosopher, but rather an "informational chunk". He refers to the grasping of the

\section{Author \\ David Bawden, Centre for Information Science, City University, London. \\ Email: $\underline{\mathrm{db} @ \text { soi.city.ac.uk }}$}

Received 08 August 2011

Accepted 14 May 2012 
structure within this chunk as an "internal seeing or appreciating" (Kvanvig, 2003, 198). It has to cope with ambiguity, contradiction, missing information, and all the other messy features present in real-world information collections.

This is not inconsistent with the typical dictionary definition to the effect that to understand is to 'comprehend' or to 'grasp with the mind'. It does, however, go beyond this, in emphasising that that we are:

1. dealing with a large and complex body of information,

2. going beyond a simple ordering and enumerating of the contents of that set, and

3. gaining some holistic 'grasp' of the contents of the set.

It seems to have much in common with Luciano Floridi's view of knowledge, as distinct from information.

Knowledge and information are members of the same conceptual family. What the former enjoys and the latter lacks ... is the web of mutual relations that allow one part of it to account for another. Shatter that, and you are left with a ... list of bits of information that cannot help to make sense of the reality they seek to address.

(Floridi, 2011, 288)

Conversely, it should be noted that this is quite a different concept and process from Brenda Dervin's "sense-making" methods for studying information-related behaviour, although the name seems similar at first sight. Dervin's methods focus on the much more general process by which the individual makes sense of his or her world through gathering information and knowledge.

The information to be comprehended will normally be in the form of text, but may include images, diagrams or numerical data. However, we will not be dealing with methods specifically for numerical data, statistical analysis or visualisation. Methods which involve simple counting, for example, the number of times a concept is mentioned in a text, will be considered, but nothing more quantitative than that. Also included are methods that give simple graphical displays, but nothing more sophisticated in the way of visualisation. It is, of course, rather arbitrary to make this particular distinction between qualitative and quantitative study: the two merge seamlessly in practice, and few, if any, real life studies lack elements of both.

Qualitative research, which tends to focus on 'the story', is often contrasted with quantitative research, which tends to focus on 'the numbers'. In actual fact, qualitative research uses numbers, and quantitative research ... uses stories.

(Fink, 2010, 144 and 147)

However, it is necessary to make a distinction somewhere, in order to keep the discussion within bounds.

The sets of information considered may have been created as part of an experimental study, such as transcripts of interviews, or detailed accounts of observations, but will more usually have been created for other purposes; academic literature, correspondence, email records and so on. We are considering 
here a post hoc analysis and/or synthesis of documents, rather than the analysis of data carried out while data collection is in progress, or immediately after. However, we will need to consider methods for the latter, when they have relevance. The distinction is exemplified by methods considered below: ethnographic analysis deals with the data from a specific on-going study, while meta-ethnography uses the same methods to deal with a collection of information amassed earlier and typically from different sources. It is this last with which we are mainly concerned.

To clarify one point: the process with which are dealing is really one of synthesis, whereby separate parts are brought together to form a "whole" (Barnett-Page and Thomas, 2009), in this case the holistic understanding which we are seeking. But the term "analysis" is so commonly used in the literature, even for those processes clearly aiming at synthesis, that we shall not generally be concerned about this distinction. One exception is that, when results of several qualitative studies are compared, using some systematic process of the kind examined here, the term "meta-synthesis" will be preferred to the quantitative "meta-analysis" (Urquhart, 2011; Saxton, 2006).

There is no suggestion, of course, that this is a totally new idea. Although this approach does not have a specific name - indeed, it may go by several names - it has certainly been practised by library/information researchers. It is often regarded as being one of the more-or-less established methods of information analysis and synthesis, such as:

- literature analysis and synthesis;

- content and discourse analysis;

- meta-ethnography;

- historical analysis;

- literature-based philosophical and conceptual analysis;

- grounded theory.

As we shall see, there is considerable overlap between some of these methods. The complex relationships, the way in some build on others, and the extent to which they cite - or do not cite - each other, is noted by Barnett-Page and Thomas (2009).

The purpose of this paper is to examine to what extent each of these methods can contribute to the gaining of understanding, as described above, and to draw out commonalities. Wherever possible, this will be done by giving selective examples from the library/information research literature.

The test of relevance will be whether these methods have the requisite qualities qualitative, holistic, inductive - since we are seeking an understanding which we do not have at the outset. This rules out working with an existing a priori framework of understanding, as is done in methods such as framework synthesis (Barnett-Page and Thomas 2009). Methods must also be applicable to the analysis of collections of information, instantiated in sets of documents. 
We may add another requisite quality. Experience suggests that the gaining of understanding does not proceed in a linear manner; rather it is non-linear and iterative, since increasing understanding is checked and re-checked against the information base. Gorman and Clayton suggest that any qualitative analysis is necessarily iterative:

Whatever the technique involved [content analysis or ethnographic analysis] it follows a nonlinear process of seeing a pattern, returning to the data ... and exploring or confirming the pattern.

(Gorman and Clayton, 2005, 206)

However, some methods are surely more iterative than others, by their very nature, and it is likely to be these which will be of most interest.

We may also consider, though not dwell upon, the philosophical perspectives which may be most appropriate. The position here is more than a little confused. Ethnography, for example, has moved from its beginnings as a largely positivist methodology to be regarded as primarily interpretivist (Pickard, 2007), while grounded theory, in its various forms, is claimed by proponents of both perspectives as theirs (Pidgeon and Henwood, 2004). The philosophical basis, on a scale from pure realism to pure idealism, for some of these methods is reviewed by Barnett-Page and Thomas (2009), who note some real implications: iteration, for example, is more likely to be feature of methods rooted in an interpretivist position. Urquhart (2011) gives a similar discussion, particularly focusing on reviews of information behaviour research. While most methods classed as some for of synthesis or meta-synthesis are based in an interpretivist perspective, Urquhart (2011) reminds us that there is also a 'realist synthesis', aimed at providing explanation of the findings of research, and giving practically useful conclusions for policy-making (e.g. Pawson 2002; Pawson et al., 2005). In seeking to give pragmatic answers to complex questions, the first step necessary is to set up a theoretical explanatory framework, within which evidence can be placed and assessed. This clearly requires a good understanding of the issues from the outset, and the method is therefore not really relevant to our purposes.

Since we are seeking understanding, the methods adopted must, by definition, have an interpretivist character. Even mathematics, the formal and objective of disciplines, recognises the subjective element:

Understanding is a difficult thing to talk about. For one thing, it contains a subjective element, whereas drawing logical inferences appears to be an objective task that even sophisticated machines might be capable of making ... Taking ideas as primary allows us to focus on understanding. Understanding is what we strive for when we learn mathematics, that is when we attempt to master other people's ideas, but it is also what we are about when we are doing mathematics, when we try to understand some mathematical phenomenon ... 'Thinking and understanding' is [sic] intimately concerned with grasping the underlying ideas involved in a piece of mathematics.

(Byers, 2007, 26 and 254). 
However, we are not seeking a purely personal understanding or enlightenment, but one that can be communicated to, and shared with, others; one that is "objective" in the sense in which Popper (1972) uses the term. This suggests that methods which are exclusively positive (realist), and equally those that are exclusively interpretivist (idealist), are likely to be unsuitable; further than that, in prescribing a philosophical basis, it is unwise to go.

No attempt will be made to describe the methods per se, but background references are given for each, for readers unfamiliar with them. Nor, for reasons of space, can extensive examples be given: again, the reader is referred to the cited references.

\section{Literature analysis and synthesis}

This seems the most obviously relevant method to begin with, since by definition it involves analysing a set of documents to identify common themes and issues. Literature analyses and reviews come in various shapes and forms. It is worth mentioning that much debate about the nature of this process has come from the healthcare context, where systematic reviewing and the search for the best 'evidence' is a major concern (Khan et al., 2011). Although much of this debate is of wider relevance, it should be remembered that healthcare has a specific set of purposes and interests, and an unusual information base, with a strong focus on experimentally-derived and statistically valid knowledge (Robinson, 2010).

Grant and Booth (2009) identify fourteen different types of literature review, which they claim to cover all review types in existence, distinguished by the kinds of search, evaluation and analysis used. They deal with healthcare research, and so focus on the systematic review to produce the best evidence, which they describe pragmatically as "gathering research, getting rid of rubbish and summarizing the best of what remains" (Grant and Booth, 2009, 92). Although this is a specific application, their findings touch upon the wider problems of information analysis. Of their fourteen review types, the most relevant to gaining understanding appears to be what these authors categorise as the "qualitative systematic review", also referred to as "qualitative evidence synthesis" or "qualitative meta-synthesis". This is intended to integrate and compare the findings of qualitative studies. "The accumulated knowledge resulting from this process", Grant and Booth $(2009,99)$ argue, "may lead to the development of a new theory, an overarching 'narrative', a wider generalisation or an 'interpretative translation'. It looks for 'themes' or 'constructs"' or conceptual models.

It does not necessarily rely on a comprehensive search for, and analysis of, all relevant material, but may instead take a selective or purposive sample, particularly if what is being sought is a holistic interpretation, and it may not use strictly and objectively defined criteria to decide which information items to include. The results are typically presented as a qualitative narrative, eschewing graphs, tables or similar presentational techniques. Grant and Booth note that this type of reviewing is sometimes described as "meta-ethnography", which they regard as misleading, since that method can be applied to many types of qualitative research, not just ethnographies; we will return to this point later. 
This seems to be close to the context of gaining understanding described above. Indeed, in an earlier discussion of this type of review, Booth $(2006,422)$ specifically states that it is "interpretative in broadening understanding of a particular phenomenon".

Urquhart (2010) uses the term "critical interpretive synthesis" to mean an apparently very similar concept, noting that it is well suited to dealing with a mix of quantitative and qualitative material, and to handling a relatively large body of information; larger than could be handled by techniques such as metaethnography. She suggests that the method borrows some ideas from grounded theory, to be discussed later. Barnett-Page and Thomas (2009) suggest that this is an adaptation of meta-ethnography, albeit with some techniques borrowed from grounded theory.

Grant and Booth note that:

methods for qualitative systematic review are still in their infancy and there is considerable debate about when specific methods or approaches are appropriate.

(Grant and Booth, 2009, 100)

It is an approach which has not yet found great application in the information sciences: Urquhart (2010) notes that most reviews in library/information science fall into the categories, as defined by Grant and Booth, of "narrative review" or "mapping review".

Unfortunately, this qualitative style of systematic review is sometimes regarded as rather second-rate. Fink (2010), writing from the perspective of a medical expert, distinguishes just two kinds of review: "research reviews", equivalent to the systematic reviews noted above, and "descriptive syntheses or reviews". The latter are categorised as those where:

reviewers use their own knowledge and experience to synthesise the literature by evaluating similarities and differences in the purposes, methods and findings of high-quality research.

(Fink, 2010, 206)

This, rather than the systematic/research style, seems to approach closer to the creation of understanding, but Fink makes it clear that this is a style one uses when good quality experimental reports are lacking; it is of some value, but distinctly second best. Nonetheless, Fink's emphasis on the fact that the validity of such a review depends on "the subject matter expertise and critical imagination of the reviewer" (Fink, 2010, 206) is interesting, and will be addressed later.

\section{Content and discourse analysis}

Content analysis is generally thought of as a quantitative technique for analysing text documents. The frequency of occurrence of words and phrases, or of word and phrases expressing concepts, are measured, sometimes with aspects of their position and context within a document included (Franzosi, 2004). Westbrook (1994) has pointed out that content analysis may be an intuitively appealing technique to those from an information science background, as the processing of 
coding concepts and searching for patterns within information resonates with familiar activities such as indexing or classification.

Lee and Fielding (2004) point out that, although not usually a descriptive technique, content analysis can have value for qualitative analysis, as a starting point for large sets of information. White and Marsh (2006), reviewing applications of content analysis in library/information science, suggest that it is usable in quantitative, qualitative or mixed-method studies. Gorman and Clayton similarly suggest that content analysis may be used in conjunction with qualitative methods, or in a way removed from the strictly quantitative paradigm. They suggest a kind of 'informal' content analysis, particularly appropriate for the analysis of documents:

without necessarily counting frequency of occurrence, the researcher notes the recurring themes and concerns ... and also perhaps those issues which did not receive great attention.

(Gorman and Clayton 2005, 215)

They propose that this may be particularly helpful in historical research, to see which issues were of concern at the time. For examples of content analysis used in a qualitative way, see Bawden and Rowlands (1999), Robinson (2007), Garner, Davidson and Williams (2008), Dennis and Bower (2008), and Manzuch (2009).

Discourse analysis is a primarily qualitative technique for analysing the way in which words and phrases are used in texts, focusing on underlying meaning rather than explicit content; the way in which concepts and issues are mentioned, and what this shows about how they are understood. There are several variants and sub-variants of the technique: as Potter $(2004,616)$ notes, "there is no single recipe for doing discourse analysis". For an overview of discourse analysis in the information sciences, see Budd (2006); for examples, see Kouper (2010), Foster (2009), Nahl (2007), and Haider and Bawden (2007).

What may be seen as an extension of discourse analysis is the 'meta-narrative' approach, whereby the analysis of a concept which may understood differently depending on the context is performed with a 'story' as unit of analysis, yielding a series of meta-narratives, from which themes may be identified (Greenhalgh et al., 2005; Barnett-Page and Thomas 2009).

Neither content analysis nor discourse analysis is of itself likely to suffice for our purpose of gaining understanding. They may, however, be of value as a preliminary stage: content analysis to identify the issues to be addressed, and discourse analysis to clarify their nature.

\section{Meta-ethnography}

It may seem strange to introduce ethnography in the context of the analysis of a set of documents. Ethnography as a research method grew out of anthropology: it was a means of studying a society through a deep immersion in its cultural milieu. Anthropologists entered some community or society, often an exotic and far-away one, and spent long periods collecting data. Oates (2006) and Pickard (2007) discussing the comparatively un-exotic topic of research on information systems 
and services - note that the ethnographer must spend considerable time both observing in the field and also handling the copious data thus collected; likewise Denscombe (2010), on the application of the method in social research generally.

There are some features of the approach which have relevance to the seeking of understanding from set of information. It is an approach, as Denscombe (2010) emphasises, which seeks holistic understanding, and which is iterative in its nature; indeed Pickard $(2007,113)$ regards ethnography as the iterative methodology par excellence, since "there are no dividing lines between collecting data, analysing data, reflecting, interpreting and writing".

While the approach is usually associated with empirical data collection, Denscombe (2010) describes a style of ethnography based on examination of documents: specifically public and private archive material, diaries, letters, etc., in a kind of historical ethnography in the research of a life history. He emphasises again the length of time necessary for ethnographic work, even when documentbased. Gorman and Clayton recommend Spradley's (1979) model of ethnographic analysis as a "practical analytical map" for analysing qualitative data from any information-related research (Gorman and Clayton, 2005, 215).

Furthermore, while ethnography typically analyses a single isolated arena of study, "meta-ethnography" has been recognised for over twenty years as a style of analysing the results of studies which have produced primarily qualitative information (Noblit and Hare, 1988); since its initiation, there have emerged several variants (Barnett-Page and Thomas 2009). Urquhart (2010) suggests that the main value of meta-ethnography is that it can explore and explain differences between experimental studies in a systematic way, but that the degree of detail required means that it may be restricted to relatively small sets of information. She gives an example of a meta-synthesis of reviews of information behaviour studies, suggesting - with commendable honesty - that it was planned along meta-ethnographic lines, but the final product, for lack of time, was nearer a critical interpretive synthesis (Urquhart, 2011).

As noted above, Booth and Grant (2009) suggest that the term has been used to describe some qualitative literature analyses aimed at providing evidence for healthcare practice. Booth (2006) notes that the term is used to refer to analyses aimed at drawing out themes, concepts, or even metaphors, as ways of understanding the material.

By definition, ethnography's concern is with the social world. It seems reasonable to suggest that an ethnographic approach may be particularly appropriate when the understanding to be gained relates to social issues.

\section{Historical analysis}

Since our interest is in dealing with sets of documents created in the past, rather than with data being created in the present, it could be argued that all of the methods discussed in this paper are forms of historical analysis. In any case, there is clearly much in common between the historians and other researchers seeking understanding from information in documents. 
Both Gorman and Clayton (2005) and Pickard (2007) emphasise the significance of historical research for the information disciplines: indeed Pickard regards it as a core professional competence. There are evident similarities between historical analysis and other methods: we have already noted Denscombe's mention of ethnography, and Gorman's and Clayton's of content analysis, in historical contexts. The latter authors also mention the use of discourse analysis, while Pickard describes the value of grounded theory - either in its more prescriptive Straussian sense, or the more open methods of Glaser - for information history studies.

Other general similarities are evident. Historical research is usually qualitative and invariably interpretive; and a disciplined and well-documented interpretation is necessary to avoid the Scylla and the Charybdis of (respectively):

scissors-and-paste history, without meaning or significance, or ... propaganda or historical fiction.

(Carr, 1961, 29)

Equally invariably it follows an iterative process. Gorman and Clayton (2005) and Pickard (2007) both quote Carr's description of historical research as:

a continuous process of interaction between the historian and his facts ... the two processes [analysis and writing] go on simultaneously and are, in practice, part of the same process.

(Carr, 1961, 29-30)

Critical historical thinking and critical historical writing are inextricably intertwined. The non-linear process here is perhaps closer to that involved in the seeking of understanding than that identified in ethnography, for example: since here the iteration involves going back to examining the documents, rather than collecting further evidence.

Of course, the distinctive feature of historical analysis is its concern for chronology. Events happen, and facts are situated, in an order in time, and that order is significant. It alone allows for consideration of change through analysis of cause and effect, of development, of influence, of motivation etc. For accounts of general historical methodology, see Tosh (2010) and Jordanova (2006).

Other distinctive aspects of historical research are associated with the selection of materials for analysis, and with particular concerns for authenticity and provenance of sources and their significance and meaning at the time of their creation. There will be gaps, 'black holes', in the documentary record, in history more than in other contexts, and these must be dealt with.

Studies of this kind may be categorised as belonging to the newly named discipline of "information history", which examines how information has been understood and used in the past; see for example Weller and Bawden (2005; 2006), and the papers in Weller (2011). Others focus on the history of particular libraries, or information organisations. But a much wider range of information analysis and synthesis in the information disciplines benefit from a chronological dimension. Examples of literature analyses based on a chronology are those 
dealing with documents (Buckland, 1998), user needs (Maceviciute, 2006), knowledge management (Koenig and Neveroski, 2008), relevance (Mizzaro, 1998; Nolin 2009) and digital literacy (Bawden, 2008).

Historical research is a major example of the gaining of understanding from analysis of documents. It has some unique aspects, which may be particularly valuable when chronology is an important feature.

\section{Literature-based philosophical and conceptual analysis}

Here we consider the kinds of studies which set out to analyse, clarify and explain concepts, issues and ideas in some body of literature. This is, if done carefully and logically, an exercise in philosophy. Philosophy is applied to, and within, the information sciences in several different ways (Furner 2010; Bawden and Robinson, 2012). Our concern is here with one of its functions: providing what Furner terms " "proper' (i.e. epistemically valuable) analysis of concepts that are central to Information Studies" (Furner, 2010, 183), and of which he gives examples. The most important are those analyses based on a large body of literature, rather than those carried out from a de novo consideration of the subject; hence the qualification "literature-based" in the heading. Studies of this kind are to be found on a spectrum, from solidly and explicitly grounded in philosophy, to less rigorous analysis and explication of concepts. Examples are analyses of "subject" (Hjørland, 1992), "digital libraries" (Bawden and Rowlands, 1999), “digital literacy” (Bawden, 2001), "relevance” (Borlund, 2003), "information avoidance" (Case et al., 2005), "knowledge" (Meyer and Sugiyama, 2007), "truth" (Labaree and Scimeca, 2008), "meaning" (Thornley and Gibb, 2009) and "information literacy 2.0" (Spiranec and Banek Zorica, 2010).

De novo philosophical analysis, considering the nature of concepts from scratch with little reference to the literature, may be a useful preliminary step for gaining understanding, in clarifying the nature of the concepts to be considered. Full and detailed philosophical analysis, however, takes us rather away from our main theme.

\section{Grounded theory}

Grounded theory is, notoriously, not a research method in itself, but rather a general strategy - or rather a set of alternative, and arguably competing, strategies - for an integrated and iterative approach to collection and analysis of information in any kind of qualitative research; Pidgeon and Henwood (2004) provide a clear overview. Pickard (2007) and Tan (2010) give detailed and sympathetic descriptions of its application within information research; for a more critical view, see Seldon (2005).

In the context of information systems research, Oates (2006) notes that grounded theory is an inductive approach, whereby concepts and theories emerge from the data. When combined with its inarguably iterative nature, this suggests it is highly relevant to our theme. Oates, however, goes on to point out that:

unfortunately, many researchers now claim that they are using grounded theory or 'a grounded theory-type approach', when all they are doing is analysing 
inductively their qualitative data for themes.... Grounded theory has particular practices incorporated within it, which address the selection of people and instances to include in the research, the way the data is analysed and the kind of theory that is generated.

(Oates, 2006, 274)

Even more bluntly, Denscombe $(2010,120)$ writes that the term may be used to justify "sloppy research", which ignores the analytical rigour required by true grounded theory.

Urquhart (2010) suggests that both meta-ethnography and the "qualitative synthesis" style of literature review borrow some ideas from grounded theory. A specifically named method, thematic synthesis, has combined concepts of grounded theory and meta-ethnography, in which freely coded concepts are iteratively combined in "descriptive themes" and thence into "analytical themes" (Thomas and Harden, 2008). Pickard (2007) makes a convincing case for the value of "memo writing", in the grounded theory sense of the term, even when not applying any other parts of the method.

Grounded theory, in any of its specific manifestations, does not seem appropriate for our purposes, but its concepts and character are likely to be useful in informing approaches to gaining understanding. These approaches have been described earlier in this paper.

\section{Conclusions}

We have seen that ways of gaining understanding from a body of information instantiated in documents are to be found within research in the information sciences. But the gaining of understanding is not fully developed, has no consistent terminology, and there is no agreed best way of going about it.

The most appropriate methods seem to those categorised as "critical interpretive synthesis', as these are able to deal with large sets of diverse forms of information, and proceed in a non-linear and holistic way. We can be more definite, without being unduly prescriptive, by suggesting that a process of this sort can be carried out in one of three 'styles', according to the kind of understanding sought, expressed as the kind of themes which will emerge:

- a meta-ethnographic style, for social understanding;

- a historical style, for chronological understanding;

- a conceptual style, for epistemological understanding.

The process may be preceded either by content analysis, discourse analysis or philosophical analysis, to identify and clarify the questions to be addressed.

It is inappropriate to try to specify in any more detail the precise methods to be followed, and indeed it is noticeable that commentators in this area rarely deal in detail with the practicalities of such studies: Pickard (2007) with her recommendations of concept maps, rich pictures, and the "constant comparative analysis" of grounded theory, is an exception. Jahangirian et al. (2011) address the practicalities of handling very large sets of information for review. 
Finally, we may return to the point made by Fink (2010) about the need for subject knowledge on the part of those who carry out such "understandinggaining" studies. Even though we are considering only research in the information sciences, this covers a wide area of necessary background knowledge. Perhaps an increase in number and visibility of such studies will both draw attention to the need for such knowledge, and contribute to its spread.

\section{References}

Barnett-Page, E. and Thomas, J. (2009) Methods for the synthesis of qualitative research: a critical review, BMC Medical Research Methodology [online], 9(59). URL: http://www.webcitation.org/5shAOY1P7 [accessed 2012].

Bawden, D. (2001) Information and digital literacies: a review of concepts, Journal of Documentation, 57(2), 218-259.

Bawden, D. (2008) Origins and concepts of digital literacy. In: Lankshear, C. and Knobel, M. (eds.), Digital literacies: concepts, policies and practices. New York NY: Peter Lang. 17-32.

Bawden, D. and Robinson, L. (2012) Introduction to information science, London: Facet.

Bawden, D. and Rowlands, I. (1999) Digital libraries: assumptions and concepts, Libri, 4994, 181-191.

Booth, A. (2006) 'Brimful of STARLITE': towards standards for reporting literature searches, Journal of the Medical Library Association, 94(4), 421-429.

Borlund, P. (2003) The concept of relevance in IR, Journal of the American Society for Information Science and Technology, 54(1), 913-925.

Buckland, M. K. (1998) What is a 'document'? In: Hahn, T. B. and Buckland, M. (eds.) Historical studies in information science. Medford, NJ: Information Today. 215-220.

Budd, J. M. (2006) Discourse analysis and the study of communication in LIS, Library Trends, 55(1), 65-82.

Byers, W. (2007) How mathematicians think: using ambiguity, contradiction and paradox to create mathematics, Princeton and Oxford: Princeton University Press.

Carr, E. H. (1961) What is history?, Harmondsworth: Penguin.

Case, D. O., Andrews, J. E, Johnson, J. D. and Allard, S. L. (2005) Avoiding versus seeking: the relationship of information seeking to avoidance, blunting, coping, dissonance and related concepts, Journal of the Medical Library Association, 93(3), 353-362.

Dennis, B. W. and Bower, T. (2008) Using content analysis software to analyze survey comments, Portal: libraries and the academy, 8(4), 423-437.

Denscombe, M. (2010) The good research guide: for small-scale social research projects. $4^{\text {th }}$ ed. Maidenhead: McGraw Hill. 
Fink, A. (2010) Conducting research literature reviews: from the internet to paper. $3^{\text {rd }}$ ed. Thousand Oaks, CA: Sage.

Floridi, L. (2011) The philosophy of information. Oxford: Oxford University Press.

Foster, J. (2009) Understanding interaction in information seeking and use as a discourse: a dialogic approach, Journal of Documentation, 65(1), 83-105.

Franzosi, R. P. (2004) Content analysis. In: Hardy, M. and Bryman, A. (eds.), Handbook of data analysis. London: Sage. 547-565.

Furner, J. (2010) Philosophy and information studies, Annual Review of Information Science and Technology, 44, 161-200.

Garner, J., Davidson, K. and Williams, V. K. (2008) Identifying serials trends through twenty years of NASIG conference proceedings: a content analysis, Serials Review, 34(2), 88-103.

Gorman, G. E. and Clayton, P. (2005) Qualitative research for the information professional: a practical handbook. London: Facet.

Grant, M. J. and Booth, A. (2009) A typology of reviews: an analysis of 14 review types and associated methodologies, Health Information and Libraries Journal, 26(2), 91-108.

Greenhalgh, T., Robert, G., Macfarlane, F., Bate, P., Kyriakidou, O. and Peacock, R. (2005) Storylines of research in diffusion of innovation: a meta-narrative approach to systematic review, Social Science and Medicine, 61(2), 417-430.

Haider, J. and Bawden, D. (2007) Conceptions of 'information poverty' in LIS: a discourse analysis, Journal of Documentation, 63(4), 534-557.

Hjørland, B. (1992) The concept of 'subject' in information science, Journal of Documentation, 48(2), 172-200.

Jahangirian, M., Eldabi, T., Garg, L., Jun, G. T., Naseer, A., Patel, B., Stergioulas, L. and Young, T. (2011) A rapid review method for extremely large corpora of literature: applications to the domains of modelling, simulation and management, International Journal of Information Management, 31(3), 234-243.

Jordanova, L. (2006) History in practice. $2^{\text {nd }}$ ed. London: Bloomsbury Academic.

Khan, K. S., Kunz, R., Kleijnen, J. and Antes, G. (2011) Systematic reviews to support evidence-based medicine $2^{\text {nd }} \mathrm{ed}$. London: Royal Society of Medicine.

Koenig, M. and Neveroski, K. (2008) The origins and development of knowledge management, Journal of Information and Knowledge Management, 7(40), 243254.

Kouper, I. (2010) Information about the synthesis of life-forms: a documentoriented approach, Journal of Documentation, 66(3), 348-369.

Kvanvig, J. L. (2003) The value of knowledge and the pursuit of understanding. Cambridge: Cambridge University Press. 
Labaree, R. V. and Scimeca, R. (2008) The philosophical problem of truth in librarianship, Library Quarterly, 78(1), 43-70.

Lee, R. M. and Fielding, N. G. (2004) Tools for qualitative data analysis. In: Hardy, M. and Bryman, A. (eds.) Handbook of data analysis. London: Sage. 529546.

Maceviciute, E. (2006) Information needs research in Russia and Lithuania, 1965-2003, Information Research [online], 11(3), paper 256. URL: http://InformationR.net/ir/11-3/paper256.html [accessed 2012].

Manzuch, Z. (2009) Archives, libraries and museums as communicators of memory in the European Union projects, Information Research [online], 14(2), paper 400. URL: http://informationr.net/ir/14-2/paper400.html [accessed 2012].

Meyer, B. and Sugiyama, K. (2007) The concept of knowledge in KM: a dimensional model, Journal of Knowledge Management, 1191, 17-35.

Mizzaro, S. (1998) Relevance: the whole history. In: Hahn, T. B. and Buckland, M. (eds.) Historical studies in information science, Medford NJ: Information Today. 221-244.

Nahl, D. (2007) A discourse analysis technique for charting the flow of microinformation behaviour, Journal of Documentation, 63(3), 323-339.

Noblit, G. W. and Hare, R. D. (1988) Meta-ethnography: synthesizing qualitative studies. Newbury Park CA: Sage.

Nolin, J. (2009) 'Relevance' as a boundary concept: reconsidering early information retrieval, Journal of Documentation, 65(5), 745-767.

Oates, B. J. (2006) Researching information systems and computers, London: Sage.

Pawson, R. (2002) Evidence-based policy: the promise of 'realist synthesis', Evaluation, 8(3), 340-358.

Pawson, R., Greenhalgh, T., Harvey, G. and Walshe, K. (2005) Realist review: a new method designed for complex policy interventions, Journal of Health Services Research and Policy, 10(Supplement 1), 21-34.

Pickard, A. J. (2007) Research methods in information. London: Facet.

Pidgeon, N. and Henwood, K. (2004) Grounded theory. In: Hardy, M. and Bryman, A. (eds.) Handbook of data analysis. London: Sage. 625-648.

Popper, K. R. (1972) Objective knowledge: an evolutionary approach. Oxford: Clarendon Press.

Potter, J. (2004) Discourse analysis. In: Hardy, M. and Bryman, A. (eds.) Handbook of data analysis. London: Sage. 607-624.

Robinson, L. (2010) Understanding healthcare information. London: Facet.

Robinson, L. (2007) Impact of digital information resources in the toxicology literature, Aslib Proceedings, 59(4-5), 342-351. 
Saxton, M. L. (2006) Meta-analysis in library and information science: method, history and recommendations for reporting research, Library Trends, 55(1), 158170.

Seldon, L. (2005) On grounded theory: with some malice, Journal of Documentation, 61(1), 114-129.

Spiranec, S. and Banek Zorica, M. (2010) Information literacy 2.0: hype or discourse refinement?, Journal of Documentation, 66(1), 140-153.

Spradley, J. P. (1979) The ethnographic interview. New York NY: Harcourt Brace Jovanovich.

Tan, J. (2010) Grounded theory in practice: issues and discussion for new qualitative researchers, Journal of Documentation, 66(1), 93-112.

Thomas, J. and Harden, A. (2008) Methods for the thematic synthesis of qualitative research in systematic reviews, BMC Medical Research Methods [online], 8(45). URL: http://www.biomedcentral.com/1471-2288/8/45 [accessed 2012].

Thornely, C. and Gibb, F. (2009) Meaning in philosophy and meaning in information retrieval (IR), Journal of Documentation, 65(1), 133-150.

Tosh, J. (2010) The pursuit of history. $5^{\text {th }}$ ed. Harlow: Longman.

Urquhart, C. (2010) Systematic reviewing, meta-analysis and meta-synthesis for evidence-based library and information science, Information Research [online], 15(3), paper 708. URL: http://InformationR.net/ir/15-3/colis7/colis708.html [accessed 2012].

Urquhart, C. (2011) Meta-synthesis of research on information seeking behaviour, Information Research [online], 16(1), paper 455. URL:

http://InformationR.net/ir/16-1/paper455.html [accessed 2012].

Weller, T. (2011) Information history in the modern world: histories of the information age. Basingstoke: Palgrave MacMillan.

Weller, T. and Bawden, D. (2005) The social and technological origins of the information society: an analysis of the crisis of control in England, 1830-1890, Journal of Documentation, 61(6), 777-802.

Weller, T. and Bawden, D. (2006) Individual perceptions: a new chapter on Victorian information history, Library History, 22(2), 137-156.

Westbrook, L. (1994) Qualitative research methods: a review of major stages, data analysis techniques and quality controls, Library and Information Science Research, 16(3), 241-254.

White, M. D. and Marsh, E.E. (2006) Content analysis: a flexible methodology, Library Trends, 55(1), 22-45. 


\section{Open access and copyright}

Library and Information Research is an open access journal. A freely available copy of this paper may be downloaded from the journal's website:

http://www.cilipjournals.org.uk/lir

Copyright and associated moral rights in works published in Library and Information Research are retained by the author(s) but this paper may be used freely, with proper attribution, in educational and other non-commercial settings. 